\title{
Ultrasonic Assessment of Adulteration in Edible Oils Using Rheological Parameters
}

\author{
Bibha Kumari ${ }^{1}$, R. P. Yadav ${ }^{2}$, P. P. Singh ${ }^{3}$ \\ ${ }^{1,3}$ Department of Humanities \& Applied Science, Invertis University, Bareilly-243123, UP, India \\ ${ }^{2}$ Regional Higher Education Office, Bareilly, UP, India
}

\begin{abstract}
Non-destructive characterization methods using the ultrasonics become very important to characterize the oils and fats.It is used as a versatile tool in study of internal structure and inherent properties of fats and oils,since it does not change the properties of the structure of materials. The ultrasonic velocity is used as a valuable tool for the study of various physical and chemical properties of the matter. The variation of rheological and ultrasonic parameters in the binary mixtures of the oils are studied and reported in present paper. The adulteration in edible oil is a deep rooted social evil, can cause several problems in edible oils application and industry. Adulteration of low quality, cheap, non-edible and toxic substance in the edible oil leads to different disease to human. Six samples ofmustard and olive oils, adulterated with cheaper oil by mixing them in different proportions, have been collected. The oil is subjected to frying temperature $200^{\circ} \mathrm{C}$ repeatedly so that compositional changes take place in the fatty acids. The changes in the quality of sample oil arestudied from the changes in the parameters such as viscosity, density, ultrasonic velocity, acoustic impedance, adiabatic compressibility and intermolecular free length, from which the adulteration in the oil can be easily perceived compared to analytical techniques. Fatty acids (FA), free fatty acids (FFA), peroxide value (PV) were used as chemical indicators of different quality of sample oil compared to ultrasonic measurements. The chemical changes are linked to changes in ultrasonic parameters, which show that ultrasound can be used to assess and monitor oil quality. The study demonstrated thatedible oils are characterized in terms of their fatty acids and its flow behaviorby ultrasonic and coupled with GC-MS.
\end{abstract}

Keywords: Olive oil, mustard oil, ultrasonic velocity, viscosity, fatty acid, peroxide value

\section{Introduction}

The ultrasonic study of adulterated edible oil with viscometry has gained much more importance in assessing the nature of molecular interaction of edible oil.In thepresent paper the variation of rheological and ultrasonic parameters in the binary mixtures of the olive and mustard oils adulterated with different proportions of cottonseed oil \&palm oilrespectively.The objectives of this paper are (1) to detect whether a sample oil is adulterated or not, (2) to identify the type of adulterants, and (3) to explore the significant parameters that can distinguish pure mustard oil and olive oil from adulterated mustard \& olive oils and classify different types of adulterants using the fatty acid profile by ultrasonic and coupled with GCMS.Characterization of vegetable oil using ultrasound is most effective and easy method to give details information about fats and oils than FT-IR, GC- MC method.The changes in the quality of sampleoil arestudied from the changes in the parameters such as viscosity, density, ultrasonic velocity, acoustic impedance, adiabatic compressibility and intermolecular free length so that the adulteration in the oil can be easily perceived.The oil is subjected to frying temperature $200^{\circ} \mathrm{C}$ repeatedly so that compositional changes take place in the fatty acids. To predict viscosity and adulteration in oil at intermediate temperatures an empirical correlation between viscosity and temperature is used.This study can be used not only to evaluate the adulteration but also the structure of the composition in oil.

\section{Methodology}

Ultrasonic method is powerful probe for characterizing physico-chemical properties and existence of molecular interaction in the mixture in addition density, viscosity and the derived acoustical \& thermodynamical parameter which provide evidence of confirmation.Characterization are done on six unheated sample ofextra virgin olive oil, pomace olive oil, cotton seed oil, cold pressed mustard oil (kachchi ghani) and palm oil. The sample oils have been adulterated by mixing cheaper oil in different proportions that is $10 \%$ and $20 \%$.To mimic the oil oxidation process during frying, the sample has been heated up to $200^{\circ} \mathrm{C}$ for two times and the temperature is maintained by a temperature controller which has a very good accuracy of $\pm 1 \%$ of error.Density and viscosity play an important role in the atomization process. The density-viscosity dependence was analyzed, showing that a good estimation of the viscosity can be obtained from the measure of the density, which is a simple and time effective process.

To find the change in viscosity with temperature a Brookfield viscometer was used. The measurements were made at room temperature by directly inserting a probe into the sample. The experiments were carried out in triplicate and the average was considered. The ultrasonic measurments was carried out by using a variable path Ultrasonic Interferometer (Mittal Enterprises, Model M - 80) operating at the frequency $5 \mathrm{MHz}$. Each fat and oil molecule has a set of unique physical, chemical, and compositional parameters by which it can be recognized. To detect edible oils and fats adulteration, it is possible to use both major and minor components as detection tool.Edible oil has the composition of fatty acids and triglycerides.[1]Fatty acids are straight chain aliphatic compounds terminated with a $\mathrm{COOH}$ group and triglycerides as esters of the propane 1, 2, 3- triol with three fatty acid residues as shown in fig.1 \&fig.2. [2]

\section{Volume 6 Issue 1, January 2017




\section{International Journal of Science and Research (IJSR) \\ ISSN (Online): 2319-7064}

Index Copernicus Value (2015): 78.96 | Impact Factor (2015): 6.391

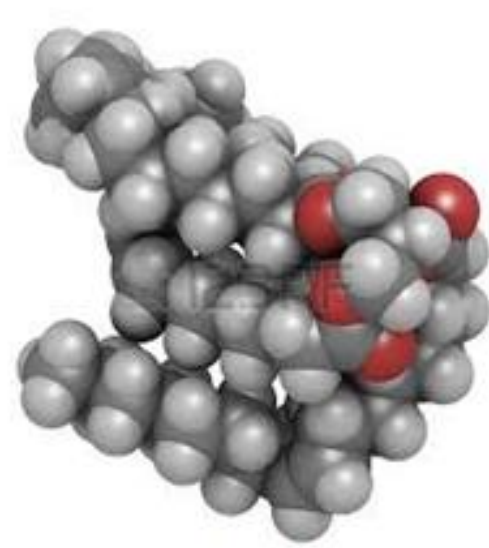

Figure 1

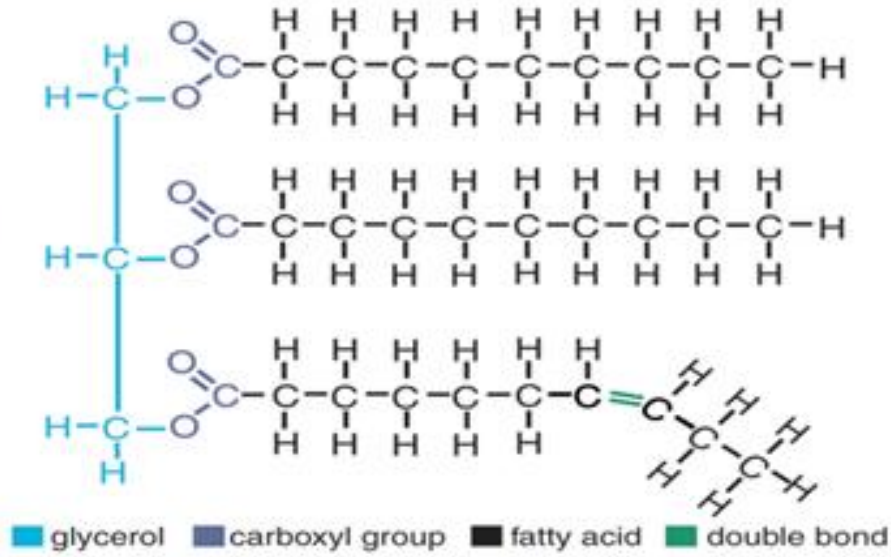

Figure 2

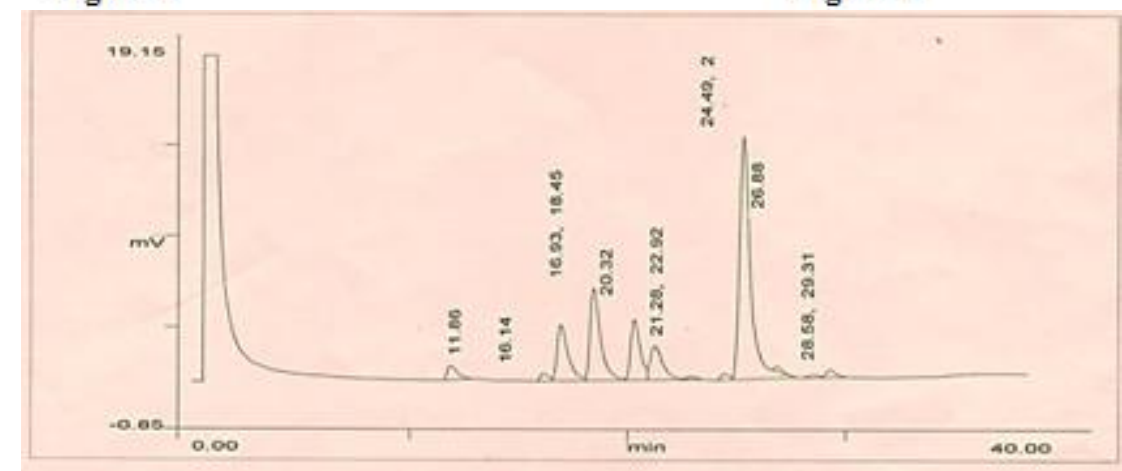

Figure 3: Gas Chromatograph trace for mustard oil sample

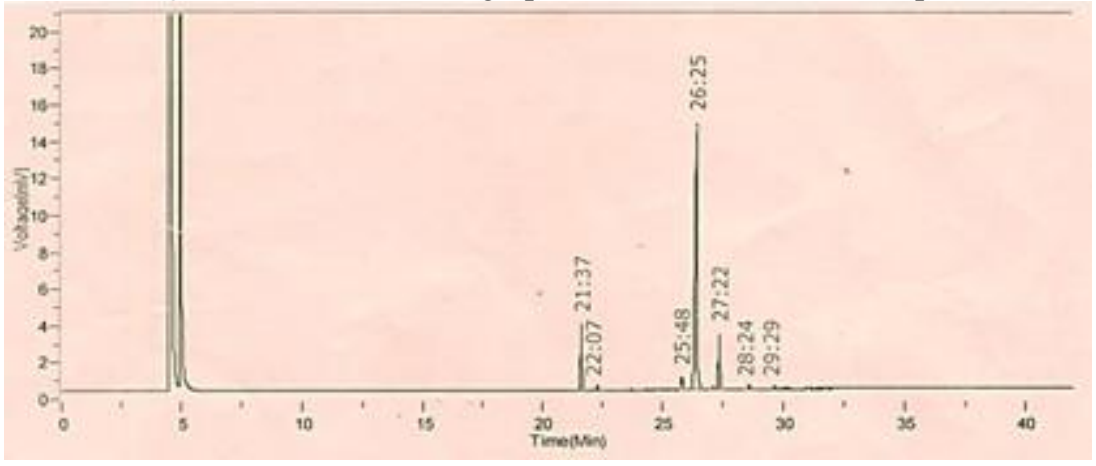

Figure 4: Gas Chromatograph trace for olive oil sample

Table 1: Free fatty acid value, peroxide value, iodine value and saponification value of analyzed sample oil

\begin{tabular}{|c|c|c|c|c|}
\hline Vegetable oil sample & FFA & $\mathrm{PV}(\mathrm{meq}) / \mathrm{kg}$ & $\mathrm{IV}$ & $\mathrm{SV}$ \\
\hline MO & $4.31 \%$ & 4.15 & 106.85 & 172.15 \\
\hline MO+PO10\% & $3.69 \%$ & 8.90 & 97.71 & 172.24 \\
\hline MO+PO 20\% & $4.19 \%$ & 10.92 & 95.57 & 173.33 \\
\hline Olive & $0.11 \%$ & 9.40 & 83.79 & 188.45 \\
\hline Olive+Cotton10\% & $0.11 \%$ & 9.92 & 85.31 & 184.46 \\
\hline Olive+Cotton20\% & $0.11 \%$ & 10.01 & 87.31 & 188.41 \\
\hline
\end{tabular}

FFA- Free fatty acid PV- Peroxide Value IV- Iodine Value SV-Saponification Value

\section{Results and Discussion}

Free fatty acid value, peroxide value, iodine value and saponification value of analyzed sample oil have been from table no.1show the marked difference in adulterated oil. Fatty acid composition is useful to detect adulteration of the following sampleoils.[3]Gas chromatograph analysis of mustard and olive oil has been shown in fig. 3 and 4.The fatty acid composition of sample oil has been determined by Gas chromatography (GC) shown in table no. 2

Table 2: Fatty acid composition of the analyzed edible oils (wt. \%)

\begin{tabular}{|c|c|c|c|c|c|}
\hline Vegetable oil sample & $\begin{array}{c}\text { Hexadecanoic } \\
\text { Palmitic } \\
(\mathrm{C} 16: 0)\end{array}$ & $\begin{array}{c}\text { Octadecenoic } \\
\text { Oleic } \\
(\mathrm{C} 18: 1)\end{array}$ & $\begin{array}{c}\text { Octadicadienoic } \\
\text { Linoleic } \\
(\mathrm{C} 18: 2)\end{array}$ & $\begin{array}{c}\text { Octadicatrienoic } \\
\text { Linolenic } \\
(\mathrm{C} 18: 3)\end{array}$ & $\begin{array}{c}\text { Docosenoic } \\
\text { Erucic } \\
(\mathrm{C} 22: 1)\end{array}$ \\
\hline MO & 2.471 & 10.925 & 17.102 & 9.983 & 47.0663 \\
\hline MO+PO10\% & 8.100 & 17.166 & 12.910 & 7.540 & 42.2820 \\
\hline MO+PO 20\% & 10.901 & 17.374 & 14.889 & 6.808 & 37.214 \\
\hline Olive & 11.804 & 73.759 & 9.729 & 0.678 & ----- \\
\hline Olive+Cotton10\% & 11.185 & 70.984 & 14.686 & 0.639 & ---- \\
\hline Olive+Cotton20\% & 14.112 & 66.452 & 15.565 & 0.177 & ----- \\
\hline
\end{tabular}

Volume 6 Issue 1, January 2017 www.ijsr.net 


\section{International Journal of Science and Research (IJSR) \\ ISSN (Online): 2319-7064 \\ Index Copernicus Value (2015): 78.96 | Impact Factor (2015): 6.391}

Linoleic acid consists of two conjugated double bonds which are more liable to oxidation than the single double bond in oleic acid. The oil with a rich content of oleic acid is expected to have longer life time than oil with a large content of Linoleic acid.It has been clear from Table 2in the mustard oil and palm oil, oxidation induced more pronounced compositional changes: contents of linoleic and linolenic acids dropped the concentration while oleic acid increases .In olive oil and cottonseed oil, oxidation reduces the contents of oleic acid and while increases of saturated fatty acid constituents (palmitic) and linoleic acid. Erucic acid, presents in mustard oil only, also reduced slightly its contents.

\section{Viscosity determination}

Ultrasonic velocity has been correlated to rheological properties of edible oils.[4]Edible oilspresent a Newtonian behavior under the conditions used for viscosity measurements. Brookfield viscometer was used to measure the viscosity of sample oil.Effectsof temperature on the kinematic viscosity of edible oils have been investigated by few researchers. [5] [6]

The most known mathematical models were developed by Vogel-Fulcher, Arrhenius and Andrade to study the effect of temperature on viscosity for a wide range of temperatures. An empirical correlation between kinematics viscosity and temperature to determine so as to predict viscosity and adulteration in oil at intermediate temperatures described by means of the Arrhenius equation.

Arrhenius equation: The following Arrhenius equation can be used to determine the activation energy of the viscous flow of oils.

$$
\eta=A e^{-E_{a} / R T}
$$

Where $\eta$ is the kinematic viscosity, $E_{a}$ is the activation energy $(\mathrm{kJ} / \mathrm{kg}), \mathrm{R}$ is universal gas constant $(8.314 \mathrm{~kJ} / \mathrm{kg}$ mol $\mathrm{K}), \mathrm{A}$ is a constant $\left(\mathrm{m}^{2} / \mathrm{s}\right)$ andT is the absolute temperature.

By applying logarithms to both sides of Equation (1) it leads to,

$$
\ln \eta=\ln \mathrm{A}-\frac{E_{a}}{R T}
$$

Equation (1) can linearize Equation (2) by applying the least-squares method and making $1 / \mathrm{T}$ the independent variable. A plot of $\ln [\eta]$ against $1 / \mathrm{T}$ showing linear graph was drawn, from which the value of Ea is evaluated. This super Arrhenius behavior of oils with temperature is illustrated in Table 3 which shows the calculated activation energy value, correlation coefficient and the value of the constant A. Figure 5 and 6 shows a plot of the variation of viscosity of the binary mixture of olive with cottonseed oil and mustard oil with palm oil.

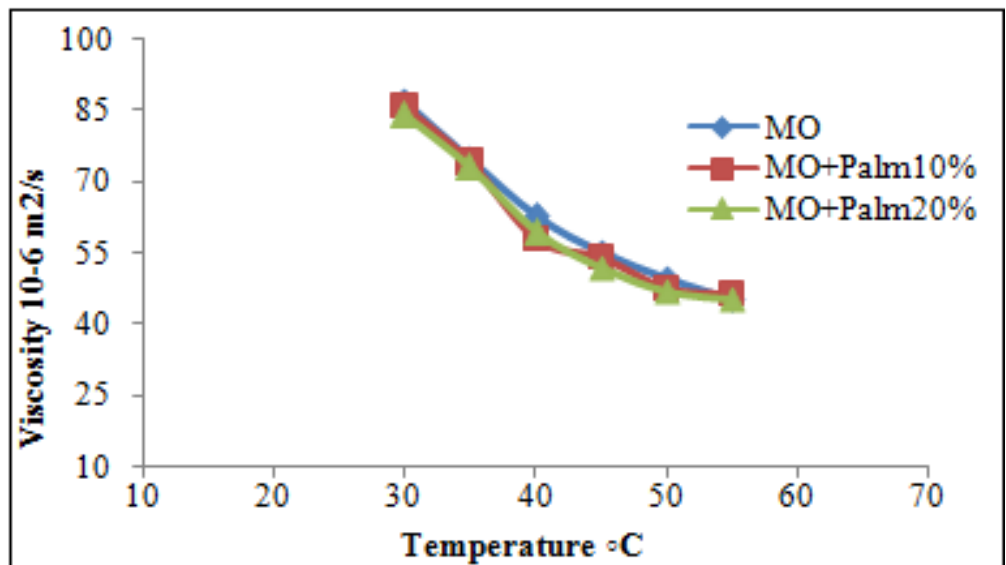

Figure 5: Change in viscosity with temperature of pure mustard oil and its mixture with palm oil.

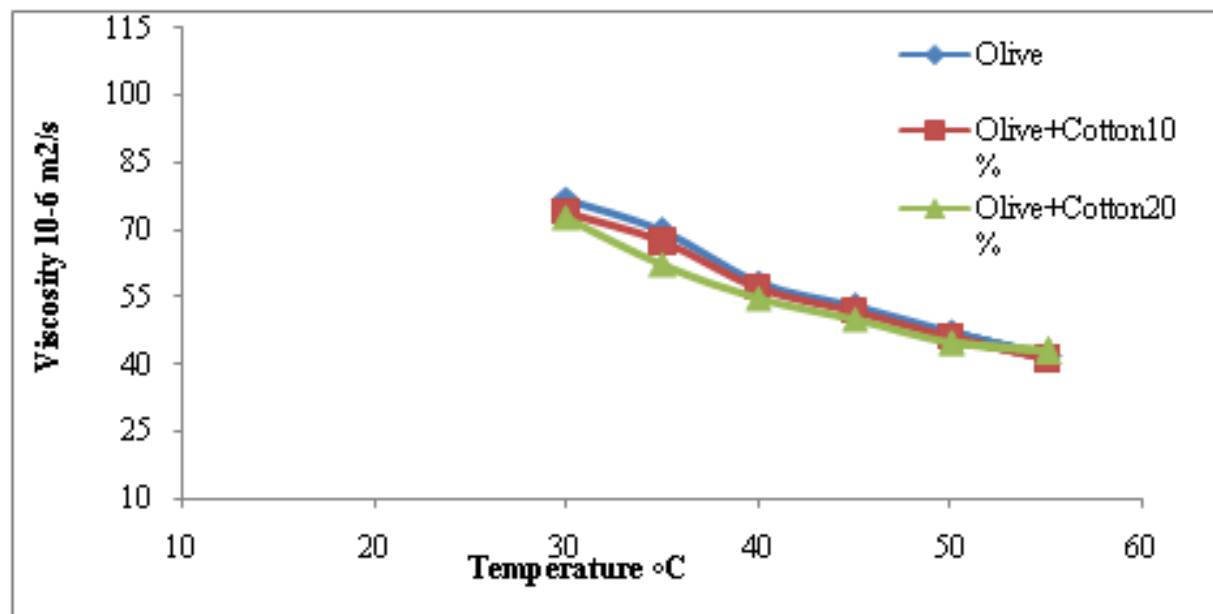

Figure 6: Change in viscosity with temperature of pure olive oil and its mixture with cottonseed oil

Volume 6 Issue 1, January 2017

www.ijsr.net

Licensed Under Creative Commons Attribution CC BY 


\section{International Journal of Science and Research (IJSR) \\ ISSN (Online): 2319-7064}

Index Copernicus Value (2015): 78.96 | Impact Factor (2015): 6.391

Table 3: Exponential (Arrhenius model) Function

\begin{tabular}{|l|c|c|c|}
\hline Vegetable oil sample & \multirow{2}{*}{$\mathrm{R}^{2}$} & \multicolumn{2}{|c|}{ Constants } \\
\cline { 3 - 4 } & & $\mathrm{A}\left(\mathrm{m}^{2 /} \mathrm{s}\right)$ & $\mathrm{E}_{\mathrm{a}}(\mathrm{KJ} / \mathrm{mol})$ \\
\hline MO & 0.999 & 91.58 & 24.03 \\
\hline MO+PO10\% & 0.997 & 79.42 & 23.02 \\
\hline MO+PO 20\% & 0.996 & 73.55 & 18.03 \\
\hline Olive & 0.992 & 115.43 & 31.99 \\
\hline Olive+Cotton10\% & 0.993 & 102.86 & 35.5 \\
\hline Olive+Cotton20\% & 0.991 & 69.99 & 24.12 \\
\hline
\end{tabular}

Table 3 shows that the activation energy of the vegetable oils ranges from 18.03 to $35.0 \mathrm{~kJ} / \mathrm{mol}$. The highest value of activation energy was observed in olive oil added with $10 \%$ of cottonseed oil. The activation energy refers to the sensitivity of the oil to the temperature and the viscosity of this mixture of oil compared to other samples and it was observed that oil which has more double bond exhibit less activation energy. The composition of polyunsaturated fatty acids in mustard oil is greater than $20 \%$, olive oil has $9 \%$ and cottonseed oil has $54 \%$ palm oil has comprises only $10 \%$. Hence using this model we can predict viscosity at any temperature, also the degree of adulteration can be estimated.Here correlation coefficient ' $R$ ' value is less and the calculated errors are high.

Table 4: Variation of parameter $(\rho),(\eta),(v),(Z),(\beta)$ and $\left(L_{f}\right)$ of unheated mustard oil and mixture of palm oil \& olive oil and mixture of cotton seed oil

\begin{tabular}{|c|c|c|c|c|c|c|}
\hline $\begin{array}{l}\text { Vegetable } \\
\text { Oil Sample }\end{array}$ & $\begin{array}{l}\text { Viscosity } \\
\eta(30 \circ \mathrm{C})\end{array}$ & $\begin{array}{l}\text { Density } \\
\rho(30 \circ \mathrm{C})\end{array}$ & $\begin{array}{l}\text { Ultrasonic velocity } \\
\mathrm{v}\left(30^{\circ} \mathrm{C}\right)\end{array}$ & $\begin{array}{c}\text { Acoustic } \\
\text { impedance }\end{array}$ & $\begin{array}{c}\text { Adiabatic } \\
\text { compressibility }\end{array}$ & Intermolecular length \\
\hline & $\mathrm{m}^{2} / \mathrm{s} 10^{-6}$ & $\mathrm{~kg} / \mathrm{m}^{3}$ & $\mathrm{~m} / \mathrm{s}$ & $\mathrm{kg} / \mathrm{m}^{2} \mathrm{~s} 10^{6}$ & $\beta N^{-1} m^{2} 10^{-10}$ & $L_{f} \times 10^{-10}$ \\
\hline MO & 87 & 906 & 1440 & 1.306 & 5.315 & 1.454 \\
\hline $\mathrm{MO}+\mathrm{PO} 10 \%$ & 86.4 & 906 & 1439 & 1.305 & 5.318 & 1.455 \\
\hline $\mathrm{MO}+\mathrm{PO} 20 \%$ & 86 & 907 & 1445 & 1.434 & 4.815 & 1.384 \\
\hline Olive & 77 & 909 & 1438 & 1.292 & 5.437 & 1.471 \\
\hline Olive+Cotton $10 \%$ & 73 & 908 & 1429 & 1.297 & 5.39 & 1.465 \\
\hline Olive+Cotton $20 \%$ & 73 & 910 & 1448 & 1.306 & 5.241 & 1.318 \\
\hline
\end{tabular}

Table 5: Variation of parameter $(\rho),(\eta),(\mathrm{v}),(\mathrm{Z}),(\beta)$ and $\left(L_{f}\right)$ of heated mustard oil and mixture of palm oil \& olive oil and mixture of cotton seed oil

\begin{tabular}{|l|c|c|c|c|c|c|}
\hline $\begin{array}{c}\text { Vegetable } \\
\text { Oil Sample }\end{array}$ & $\begin{array}{c}\text { Viscosity } \\
\eta\left(30^{\circ} \mathrm{C}\right)\end{array}$ & $\begin{array}{c}\text { Density } \\
\rho\left(30{ }^{\circ} \mathrm{C}\right)\end{array}$ & $\begin{array}{c}\text { Ultrasonic velocity } \\
\mathrm{v}\left(30^{\circ} \mathrm{C}\right)\end{array}$ & $\begin{array}{c}\text { Acoustic } \\
\text { impedance }\end{array}$ & $\begin{array}{c}\text { Adiabatic } \\
\text { compressibility }\end{array}$ & Intermolecular length \\
\hline $\mathrm{m} / \mathrm{s}^{-6}$ & $\mathrm{~kg} / \mathrm{m}^{3}$ & $\begin{array}{c}\mathrm{mg} / \mathrm{s} \\
\mathrm{m}^{2} \mathrm{~s} 10^{6}\end{array}$ & $\beta N^{-1} \mathrm{~m}^{2} 10^{-10}$ & $L_{f} \mathrm{X} 10^{-10}$ \\
\hline MO & 92.3 & 904 & 1455 & 1.316 & 5.227 & 1.443 \\
\hline MO+PO10\% & 94.8 & 897 & 1468 & 1.317 & 5.171 & 1.435 \\
\hline MO+PO 20\% & 95.3 & 898 & 1513 & 1.337 & 4.863 & 1.391 \\
\hline Olive & 87 & 902 & 1452 & 1.322 & 5.259 & 1.447 \\
\hline Olive+Cotton10\% & 84.3 & 890 & 1453 & 1.310 & 5.309 & 1.454 \\
\hline Olive+Cotton20\% & 84 & 904 & 1456 & 1.367 & 5.215 & 1.440 \\
\hline
\end{tabular}

Ultrasonic studies have enormous data in precisely understanding the molecular interactions and structural behavior of for many organic compounds.Ultrasonic velocity measurements correlated to viscosity of edible oils can be used to access oil composition and adulteration. [7] The change in ultrasonic velocity has been measured to determine the chemical structure of different oils including chain length and degree of unsaturation.Ultrasonic velocity is related to the changes in physical and chemical properties of composition of oil that determine the quality of oil.[8][9] Table 4 and 5 illustrate the variation of physical parameter like density, viscosity, ultrasonic velocity, acoustic impedance, intermolecular free length and adiabatic compressibility. Increase in viscosity may be due to longer inter chain interaction and larger stiffness of macromolecules. [10] From the table it is observed that density and viscosity of heated oils (exposed to $200^{\circ} \mathrm{C}$ temperature for two times) are greater than unheated oils. Heating the oil to smoke point for a number of cycles will increase the saturated fatty acids and triglycerides in oils. This saturated and heavy molecular compound will decrease the fluid nature of the oil and hence the density and viscosity of heated oil increases. [11]
The absorption of sound in the liquid and the coefficient of reflection at the reflector surface have been obtained through a complicated analysis of the electrical and equivalentelectrical circuits of the quartz crystal and the associated fluid column. When the condition of resonance of all parts of the system (electrical, mechanical, and acoustical) exists, the analysis of the complete electrical and equivalentelectrical circuit is greatly simplified. The ultrasonic velocity in liquid mixtures have been measured using an ultrasonic interferometer working at frequency $5 \mathrm{MHz}$ with an overall accuracyof $\pm 0.01 \mathrm{~ms}^{-1}$. The density and viscosity are measured using pycnometer and Brookfield viscometer with an accuracy of $\pm 0.2 \mathrm{~kg} \mathrm{~m}^{-3}$. The ultrasonic velocity in oils depends on the fatty materials. The fatty acids in oil get saturated by the addition as hydrogenation is one of the chemical reactions that take place when the oil is heated. The percentage of monosaturation depends on viscosity of oil.Table 4 and 5 exemplify the change in the ultrasonic velocity through the oil on heating. The saturated hydrogen bonding reduces the velocity of ultrasonic wave. The ultrasonic velocity also varies with addition of palm to mustard oil and cottonseed to olive oil at different proportion which could be used to study the adulteration in olive oil.

\section{Volume 6 Issue 1, January 2017 www.ijsr.net}




\section{International Journal of Science and Research (IJSR) \\ ISSN (Online): 2319-7064}

Index Copernicus Value (2015): 78.96 | Impact Factor (2015): 6.391

Acoustic impedance $\mathrm{Z}=\rho \mathrm{v} \mathrm{kgm}^{-2} \mathrm{~s}^{-1}$ is an important quantity which determines how much energy is transmitted and reflected by the interface separating two media of different density. Table 4 and 5 shows that heated oils illustrate more impedance than unheated oils. It is observed that addition of cottonseed oil increases the impedance whereas palm oil exhibit less impedance because palm oil even though it is composed of high percentage of saturated fatty acids the molecular weight of the short chain fatty acids are less compared to long chain fatty acids of cottonseed oil and olive oil. This study can be used to evaluate not only to adulteration but also the structure of composition in oil.

One of the important intermolecular properties of a liquid is the free length $L_{f}$ between the surfaces of the neighboring molecules and is the distance covered by the propagating acoustic waves between surfaces of the neighboring molecules in the liquid. Jacobson has given an empirical relation between ultrasonic velocity $\mathrm{v}$, the density $\rho$ and the intermolecular free length $L_{f}$ of a liquid as

$$
L_{f} \vee \rho^{1 / 2}=K
$$

Where $\mathrm{K}$ is a constant, which depends on temperature, Jacobson has given the values of this constant at various temperatures.[12][13]

In terms of the adiabatic compressibility of the liquid, the equation can be written as

$$
\begin{aligned}
& L_{f}{ }^{2}=K^{2} \beta \\
& \text { i.e. } \mathrm{Lf}=\mathrm{K} \sqrt{ } 1 /\left(\mathrm{v}^{2} \rho\right)
\end{aligned}
$$

Where $\mathrm{K}$ is temperature dependent constant parameter is equal to be $631 \times 10^{-8}$ (SI units).

The deviation in ultrasonic velocity depends upon the increase or decrease in the free length in the sample oil after mixing. The reduced free length in oils is due to the mixing of different types of oil with different composition of long and short chain fatty acids, saturated and unsaturated compounds that changes the ultrasound velocity.This indicates that the intermolecular free length is a predominant factor in determining the sound velocity variation in the mixture as well as in the pure oil.In table 4 and 5 the reduction in the free length on the addition of palm oil shows the molecular weight of the compound in the oil lowers the ultrasonic velocity in the oils.

\section{Conclusion}

Edible oils are characterized in terms of their fatty acids and its flow behavior with temperature could be well characterized by Arrhenius model. The result shows that the oils with more double bonds appeared to have lower viscosity due to their loosely packed structure and the oil exhibit Newtonian behavior. The chemical changes (polymerization) are linked to the changes in ultrasonic parameters like ultrasonic velocity, acoustic impedance, intermolecular free length and adiabatic compressibility; hence they could be used to characterize the adulteration, monitor oil quality and thermal degradation in oils. Ultrasonic velocity is related to the changes in physical and chemical properties of composition of oil that determine the quality of edible oil.Different physical and chemical parameters of edible oil are used to monitor the compositional quality of oils. The feasibility of using viscosity and ultrasonic techniques to evaluate the quality parameters of oils recommends simple method replacing of high cost traditional analytical method other analytic methods like NMR spectroscopy, Raman Spectroscopy, near infrared (NIR) spectrometer, and Chemometrics,DSC.

\section{Acknowledgement}

The authors are thankful to the Vice chancellor of M.J.P Rohilkhand University, UPfor providing the facilities to carry out the work successfully and also to Invertis University where some work have been performed in pharmacy lab. We are also thankful to B. L. Agro oils Ltd. Bareilly for providing GLC-MS for analysis of the sample.

\section{References}

[1] Daniel Geller, P. and John, G. W. (2000). Rheology of vegetable oil analogs and triglycerides, Journal of American oil Chemical Society 77: 111-114

[2] Daniela, S. and Alessandro, P. (2010). High- power gradient diffusion NMR spectroscopy for the rapid assessment of extra virgin oil adulteration. Food Chemistry 118: 153-158.

[3] Fatty Acid Datta Book (3rd ed.), (1992). Unichema International, Gouda.

[4] Gladwell, N., Javanaud, C., Peers, K. E., \&Rahalkar, R. R. (1985).Ultrasonic behavior of edible oils: Correlation with rheology. Journal ofthe American Chemical Society, 62, 1231-1236.

[5] Anupama, G., Sharma, S.K. and Amrit P.T. (2007). An empirical correlation in predicting the viscosity of refined vegetable oils. Indian Journal of Chemical Technology 14: 642-645.

[6] RubalyaValantina, S., Chandiramouli, R. and Neelamegam, P.(2013). Detection of adulteration in olive oil using rheological and ultrasonic parameters. International Food Research Journal 20(6): 3197-3202.

[7] Aurel, P. and Dorin, D. (2007). Study of edible oils adulteration by ultrasonic attenuation, Romanian Journal of Physics 52: 641-644.

[8] Mc Clements, D.J. and M.J.W. Povey, (1992). Ultrasonic Analysis of Edible Oils and Fats, Ultrasonics 30:383-388.

[9] Coupland, J.N., and D.J. McClements, Physical Properties of Liquid Edible Oils, J. Am. Oil Chem. Soc. 74:1559-1564 (1997).

[10] Jose, B., Jose, G. P. V., Carmen, D. M. and Antonio, M. (2007). Rapid evaluation of frying oil degradation using ultrasonic technology. Food Research International 40: 406-414.

[11]Tong, W. and Jenni, B. L. (2002). Rheological and thermal Properties of soybean Oils with Modified FA Compositions. Journal of American Oil Chemical Society 79: 831-836.

[12] B. Jacobson, Acta. Chem. Scand., 5, 1214, (1951).

[13] B. Jacobson, J. Chem. Phys., 20, 927, (1952). 